\title{
INTERESTERIFICAÇÃO QUÍMICA: ALTERNATIVA PARA OBTENÇÃO DE GORDURAS ZERO TRANS
}

\author{
Ana Paula Badan Ribeiro*, Juliana Maria Leite Nóbrega de Moura, Renato Grimaldi e Lireny Aparecida Guaraldo \\ Gonçalves \\ Departamento de Tecnologia de Alimentos, Faculdade de Engenharia de Alimentos, Universidade Estadual de Campinas, \\ CP 6091, 13081-970 Campinas - SP, Brasil
}

Recebido em 19/5/06; aceito em 9/11/06; publicado na web em 28/5/07

\begin{abstract}
CHEMICAL INTERESTERIFICATION: ALTERNATIVE TO PRODUCTION OF ZERO TRANS FATS. The function of lipids in human nutrition has been intensively debated in the last decade.This context reinforces the concern about controlling the trans fat ingestion, due to its negative implications on health. Interesterification provides an important alternative to modify the consistency of oils and fats without causing formation of trans isomers. This article reports research done towards production of zero trans fats by chemical interesterification, for different industrial purposes. Aspects related to the effect of trans fats on diet, their impact on health and modifications in Brazilian legislation are also covered.
\end{abstract}

Keywords: trans fatty acids; interesterification; nutrition.

\section{LIPÍDIOS E ÁCIDOS GRAXOS TRANS (AGT)}

Óleos e gorduras comestíveis são nutrientes essenciais da dieta humana, apresentando papel vital mediante o fornecimento de ácidos graxos essenciais e energia. Em adição às qualidades nutricionais, os óleos e gorduras provêem consistência e características de fusão específicas aos produtos que os contêm, atuam como meio de transferência de calor durante o processo de fritura e como carreadores de vitaminas lipossolúveis e aroma ${ }^{1}$. Além disso, os lipídios afetam a estrutura, estabilidade, sabor, aroma, qualidade de estocagem, características sensoriais e visuais dos alimentos ${ }^{2}$.

Quimicamente, óleos e gorduras são compostos predominantemente por triacilgliceróis. Ácidos graxos saturados são menos reativos e apresentam ponto de fusão superior em relação ao ácido graxo correspondente de mesmo tamanho de cadeia com uma ou mais duplas ligações. Ácidos graxos insaturados podem existir nas configurações cis e trans, com diferentes propriedades físico químicas. Por suas características estruturais, os ácidos graxos na forma trans (AGT) têm ponto de fusão mais elevado quando comparado com seu isômero cis correspondente, mas inferior ao ponto de fusão do ácido graxo saturado com mesmo número de átomos de carbono. Assim, os isômeros trans podem ser considerados como intermediários entre um ácido graxo original insaturado e um ácido graxo completamente saturado ${ }^{2}$. A Figura 1 ilustra a estrutura espacial e ponto de fusão dos ácidos oléico, elaídico e esteárico. Os AGT de maior ocorrência são os monoinsaturados, mas vários isômeros diinsaturados ou mesmo triinsaturados podem ser formados a partir dos ácidos linoléico e linolênico ${ }^{3}$.

\section{FORMAÇÃO DOS AGT}

Os AGT estão presentes naturalmente em gorduras originadas de animais ruminantes, como resultado do processo de biohidrogenação na flora microbiana do rúmen. O teor de AGT na carne e leite varia de 1,5 a 6,5\%. O isômero trans predominante corresponde ao $\mathrm{C} 18: 111 t$, conhecido como ácido trans vacênico ou ácido rumênico ${ }^{4}$. Estima-se que 2 a $8 \%$ dos isômeros trans da

*e-mail: apaulabr@fea.unicamp.br

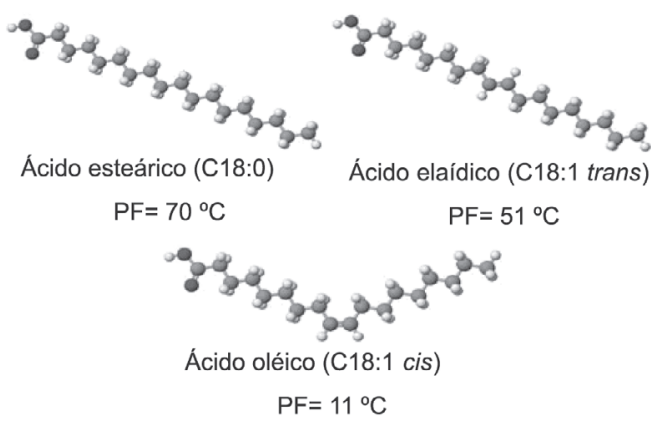

Figura 1. Estruturas e pontos de fusão dos ácidos esteárico, oléico e elaídico

dieta sejam provenientes desta fonte e veiculados principalmente pelos laticínios 5 .

Isômeros trans também podem ser formados, embora em pequenas quantidades $(0,2$ a $6,7 \%)$, no processo de desodorização de óleos vegetais e em operações de fritura de alimentos (0 a 35\%), por mecanismo induzido termicamente ${ }^{6,7}$.

Entretanto, os AGT são originados principalmente através da hidrogenação catalítica parcial de óleos vegetais ou marinhos ${ }^{8}$. Cerca de $90 \%$ dos AGT em alimentos deriva-se deste processo ${ }^{9-11}$.

A hidrogenação é realizada com o intuito de modificar a composição, estrutura e consistência de um óleo. Seu resultado é a redução do grau de insaturação do óleo e aumento de seu ponto de fusão, associado ao aumento da estabilidade oxidativa e funcionalidade das frações semi-sólidas produzidas ${ }^{12,13}$.

No Brasil, a hidrogenação comercial de óleos vegetais data da década de 50, visando a produção de gorduras técnicas ("shortenings"), margarinas e gorduras para frituras. Com o desenvolvimento de técnicas de hidrogenação seletiva, os óleos vegetais processados rapidamente substituíram as gorduras animais na dieta dos brasileiros. Estas gorduras têm sido largamente empregadas na produção de diversos alimentos, como margarinas, coberturas de chocolate, biscoitos, produtos de panificação, sorvetes, massas e batatas "chips", entre outros ${ }^{6}$.

A hidrogenação é realizada em tanques herméticos, onde o gás hidrogênio é intimamente misturado com o óleo na presença de 0,05 a $0,20 \%$ de catalisador níquel finamente dividido, a tempera- 
turas superiores a $180{ }^{\circ} \mathrm{C}$, com pressões entre 0,5 a 4 atm. No decorrer do processo, algumas das duplas ligações dos ácidos graxos são eliminadas, enquanto uma proporção significativa de duplas ligações cis são isomerizadas através de conversão cis-trans e de mudança posicional ao longo da cadeia ${ }^{3}$.

Um óleo totalmente hidrogenado é obtido quando todas as duplas ligações são saturadas no processo. Do contrário, tem-se a hidrogenação parcial, usualmente empregada ${ }^{14}$.

As características de gorduras parcialmente hidrogenadas são controladas pelas condições de hidrogenação. Os fatores envolvidos são temperatura, pressão, agitação, tipo e concentração do catalisador. $\mathrm{O}$ aumento na temperatura e/ou decréscimo na pressão acarretam o aumento da seletividade da reação, ou seja, aumentam a conversão de linoleato sobre oleato e aumentam a velocidade de formação dos $\mathrm{AGT}^{15}$.

No passado, a formação de isômeros trans foi considerada vantagem tecnológica, uma vez que, devido a seu maior ponto de fusão em relação aos correspondentes isômeros cis, favorecem a criação dos níveis de sólidos desejáveis das gorduras hidrogenadas ${ }^{16,17}$.

\section{OCORRÊNCIA DOS AGT NA DIETA}

Historicamente, o consumo mundial de AGT tem aumentado desde a década de 20, em paralelo com o aumento da produção comercial de margarinas e "shortenings", constituindo-se hoje em proporção significativa da dieta nos países ocidentais. O principal isômero é representado pelo C 18:1 trans $^{18}$.

Em geral, os AGT são consumidos em maiores quantidades nos países industrializados, com valores médios entre 2 a $8 \mathrm{~g} / \mathrm{dia}$, o que corresponde a $2,5 \%$ do total energético ou a $6-8 \%$ do total de energia proveniente de lipídios 5 .

Estima-se que o consumo de AGT nos EUA varie de 2,6 a 12,8 g/dia. Na Europa, este valor é estimado entre 0,1 a 5,5 g/dia ${ }^{19}$. No Brasil não existem estimativas consensuais sobre a ingestão diária destes compostos e os teores nos alimentos são pouco conhecidos ${ }^{20}$.

$\mathrm{O}$ teor de AGT nos produtos que contêm gordura parcialmente hidrogenada varia significativamente, até mesmo dentro de uma mesma categoria de produto. Essa variabilidade está associada às condições de hidrogenação da gordura utilizada e à natureza do produto. Os alimentos freqüentemente contêm misturas de diferentes tipos de gorduras parcialmente hidrogenadas e óleos não hidrogenados e o teor total de lipídios pode variar extremamente de um produto para outro ${ }^{21}$.

Alguns estudos têm sido realizados visando obter informações acerca dos teores de AGT nos alimentos consumidos no Brasil. Block e Barrera-Arellano ${ }^{22}$ verificaram que, na década de 90 , o conteúdo total de isômeros trans em margarinas variava de 12,3 a $38,1 \%$; nos cremes vegetais de 15,9 a $25,1 \%$ e nas gorduras técnicas, de 30 a $40 \%$. Basso e colaboradores ${ }^{23}$ obtiveram, em gorduras vegetais hidrogenadas, resultados entre 10 a $50 \%$. Grimaldi e colaboradore $^{24}$ avaliaram o teor de isômeros trans em 15 amostras de gorduras comerciais brasileiras.Os resultados encontram-se na Tabela 1 e mostram variação de 1,3 a 49,9\%.

Badolato $^{25}$ analisou 19 amostras de gorduras vegetais hidrogenadas e 14 de margarinas comercializadas no Brasil, além de 16 margarinas importadas. Foi verificada variação entre 7,3 a 40,1\% de isômeros trans do ácido octadecenóico (C 18:1) nas gorduras hidrogenadas e de 0 a $16,1 \%$ nas margarinas. Dentre estas últimas, 4 apresentaram baixo teor de AGT e uma revelou ausência dos mesmos. Este resultado foi avaliado como sinalização de que algumas indústrias brasileiras estavam adotando processos tecnológicos alternativos para minimizar a formação dos AGT. Somente 2 amostras de margarinas importadas apresentaram AGT em pequenas quantidades.
Tabela 1. Teor total de isômeros trans (\%) em amostras de gorduras presentes em produtos alimentícios comerciais brasileiros

\begin{tabular}{lc}
\hline Gorduras: Aplicação & Teor total de isômeros trans $(\%)$ \\
\hline Sopas e caldos & $32,3-36,4$ \\
Coberturas achocolatadas e & $1,3-49,9$ \\
chocolates granulados & \\
Pães e bolos & $19,5-29,9$ \\
Biscoitos recheados & $21,4-48,3$ \\
Sorvetes, cremes e margarinas & $27,0-36,3$ \\
Frituras & $7,7-30,4$ \\
Doces e confeitos & $3,3-40,3$ \\
\hline
\end{tabular}

Kawashima e Soare ${ }^{26}$ constataram teores de AGT entre 12,7 a $45,1 \%$ em 6 diferentes marcas de sorvetes cremosos. Sorvetes com gordura exclusivamente láctea não apresentaram AGT.

Os teores de AGT em batatas fritas, biscoitos e sorvetes consumidos no Rio de Janeiro foram determinados por Chiara e colaboradore $^{20}$. O valor médio destes isômeros em batatas fritas provenientes de redes de "fast food" foi de 4,74 g/100 g. Nos sorvetes, os valores variaram de 0,041 a 1,41 g/100 g e em biscoitos, de 2,81 a $5,60 \mathrm{~g} / 100 \mathrm{~g}$.

Aued-Pimentel e colaboradores ${ }^{27}$ relataram a determinação de AGT em 26 amostras de biscoitos de 6 marcas e 4 tipos diferentes: recheados, "wafer", salgados diversos e doces diversos. Os valores médios obtidos para os teores de AGT foram similares ( $3 \pm 1 \mathrm{~g} / 100$ $\mathrm{g}$ da amostra), independente de fabricantes ou tipo de biscoito. Martin e colaboradores ${ }^{6}$ avaliaram o conteúdo de AGT em amostras de biscoitos tipo "cream-cracker" consumidos no Brasil. O total de isômeros trans variou de 12,2 a 31,2\%, com média de 20,1\%.

Capriles e Arêas $^{28}$ desenvolveram salgadinhos, obtidos através de extrusão, com teores reduzidos de gordura saturada e de AGT. A gordura vegetal hidrogenada, veículo convencional para aromatização de salgadinhos, foi substituída parcial ou totalmente por óleo de canola, gerando um produto com $73,8 \%$ de redução da gordura saturada em relação aos salgadinhos comercialmente disponíveis, além de apresentar ausência de AGT. Abordagens como esta podem ser utilizadas em escala industrial, gerando produtos diferenciados e contribuindo para diminuição da ingestão de ácidos graxos saturados e AGT.

\section{AGT E SUAS IMPLICAÇÕES NA SAÚDE}

As principais preocupações com os efeitos dos AGT na saúde têm aumentado, uma vez que estes isômeros são estruturalmente similares às gorduras saturadas, modificam as funções metabólicas das gorduras poliinsaturadas e competem com os ácidos graxos essenciais em vias metabólicas complexas ${ }^{3}$.

Os isômeros cis são mais rapidamente metabolizados como fonte de energia que os trans, e são preferencialmente incorporados em fosfolipídios estruturais e funcionais. Em humanos, a incorporação dos isômeros trans nos tecidos depende da quantidade ingerida, do tempo de consumo deste tipo de gordura, da quantidade de ácidos graxos essenciais consumida, do tipo de tecido e do tipo de isômero (configuração e posição da dupla ligação na cadeia). Os teores encontrados em tecidos adiposos refletem o consumo por longo período de tempo, apresentando normalmente correlação com histórico de ingestão por mais de um ano ${ }^{29,30}$.

Os AGT foram, recentemente, incluídos entre os lipídios dietéticos que atuam como fatores de risco para doença arterial coronariana, modulando a síntese do colesterol e suas frações e atuando sobre os eicosanóides. Diversos estudos têm sugerido uma 
relação direta entre os mesmos e o aumento do risco de doenças vasculares $^{31-34}$. No entanto, estas observações são motivos de discussões que procuram avaliar se os AGT seriam melhores ou piores que os ácidos graxos saturados, sob o aspecto nutricional.

Estudos têm mostrado que a ingestão de AGT ocasiona o aumento da lipoproteína de baixa densidade (LDL) em grau similar ao causado pelos ácidos graxos saturados. Em contraste com todos os demais ácidos graxos, os isômeros trans implicam na diminuição da lipoproteína de alta densidade (HDL). Logo, a razão LDL/ HDL é afetada de modo desfavorável em comparação à modificação causada apenas pelos ácidos graxos saturados ${ }^{31,35}$. Adicionalmente, pesquisas relatam que os AGT aumentam a lipoproteína a (Lpa) e os níveis de triacilgliceróis plasmáticos, que estão independentemente associados com o aumento do risco de doenças cardiovasculares ${ }^{36,37}$

Além destes fatores, os AGT apresentam implicações na etiologia de várias desordens metabólicas e funcionais. Estudos indicam que os mesmos aumentam a fragilidade dos eritrócitos ${ }^{38}$, reduzem o consumo de oxigênio e a síntese de ATP pelas mitocôndrias ${ }^{39}$ e exibem interações competitivas com os ácidos graxos essenciais ao metabolismo ${ }^{40}$.

Entre as pesquisas voltadas para a análise da ação dos AGT sobre a saúde da criança, encontrou-se como relato comum o bloqueio e inibição da biossíntese dos ácidos graxos poliinsaturados de cadeia longa, na fase fetal e após o nascimento ${ }^{41,42}$. O estudo de Koletzko e Muller ${ }^{43}$ demonstrou correlação inversamente proporcional e significativa entre o ácido linoléico e os AGT, devido possivelmente à inibição da enzima dessaturase.

Portanto, os ácidos graxos trans deveriam apresentar prioridade nutricional secundária quando comparados aos ácidos graxos saturados, embora o consumo destes últimos também provoque efeitos desfavoráveis à saúde e deva ser minimizado ${ }^{3}$.

\section{AGT E LEGISLAÇÃO}

As questões controversas acerca do papel dos AGT na alimentação têm ocasionado modificações progressivas na legislação, visando a inclusão de maiores informações para os consumidores. A ingestão moderada deste tipo de gordura, com fins de promoção da saúde e redução do risco de doenças coronarianas, tem sido recomendada pela Organização Mundial de Saúde desde 1995. Em 1999, a "Food and Drug Administration (FDA)" sugeriu que a quantidade de AGT fosse incluída em rótulos de produtos, recomendando, quando computada em gorduras saturadas, a demarcação por símbolo informativo da quantidade específica de $\mathrm{AGT}^{44}$.

No Brasil, portaria da ANVISA, datada de 17/10/1997, estabelecia que a quantidade de AGT deveria estar computada como ácidos graxos saturados, contudo permanecendo desconhecidos os teores específicos de $\mathrm{AGT}^{45}$. Entretanto, o Código de Defesa do Consumidor Brasileiro no artigo 31, determina que os produtos ofertados à população devem apresentar declarações corretas e objetivas a respeito de suas características quanto à qualidade, quantidade e composição, entre outras, além dos riscos que oferecem à saúde dos consumidores ${ }^{46}$.

Recentemente, a Resolução RDC n ${ }^{\circ} 360$, de 23/12/2003, harmonizada no Mercosul, obriga a declaração dos AGT na rotulagem nutricional dos alimentos. As empresas tiveram prazo até 31/7/2006 para adequação, devendo o teor de gorduras trans ser declarado em relação à porção harmonizada para um determinado alimento, em conjunto com as declarações para gorduras totais e saturadas. São considerados como zero trans os alimentos que apresentarem teor de gorduras trans menor ou igual a $0,2 \mathrm{~g} /$ porção $^{47}$.

Além disso, vale ressaltar a necessidade de disponibilizar fra- ções oleosas diversificadas e com isenção de AGT para adição ao chocolate, uma vez que a Resolução RDC nº 227 (28/08/2003) define como chocolate o produto contendo no mínimo $25 \%$ de sólidos totais de cacau, permitindo assim a adição de gorduras especiais a este produto, sem sua descaracterização $0^{47}$.

\section{PROCESSO ALTERNATIVO: INTERESTERIFICAÇÃO QUÍMICA}

A interesterificação consiste em alternativa tecnológica ao processo de hidrogenação parcial, uma vez que viabiliza a produção de óleos e gorduras com funcionalidades específicas ${ }^{17}$. Devido à crescente preocupação com o impacto nutricional dos AGT na saúde, a interesterificação tem-se mostrado como o principal método para preparação de gorduras plásticas com baixos teores de isômeros trans ou mesmo ausência destes compostos ${ }^{48}$. Em contraste à hidrogenação, este processo não promove a isomerização de duplas ligações dos ácidos graxos e não afeta o grau de saturação dos mesmos ${ }^{13}$.

O processo de interesterificação permite a modificação no comportamento de óleos e gorduras, oferecendo contribuições importantes para o aumento e otimização do uso dos mesmos nos produtos alimentícios ${ }^{49}$.

A interesterificação de óleos e gorduras pode ser aplicada por diversas razões: para influenciar o comportamento na fusão, fornecendo consistência desejada em temperatura ambiente e de refrigeração; para melhorar ou modificar o comportamento cristalino, de forma a facilitar os processos de produção e, para diminuir a tendência à recristalização durante a vida útil do produto. Na reação de interesterificação os ácidos graxos permanecem inalterados, mas ocorre a redistribuição dos mesmos nas moléculas dos triacilgliceróis, resultando na modificação da composição triacilglicerídica, cuja característica final é totalmente determinada pela composição total em ácidos graxos das matérias-primas iniciais. O processo consiste, portanto, em quebra simultânea de ligações éster existentes e formação de novas ligações nas moléculas glicerídicas ${ }^{50}$.

Existem dois tipos de interesterificação em uso corrente: química e enzimática. No processo enzimático, biocatalisadores, tais como lipases microbianas, são utilizados para promover a migração acila nas moléculas acilglicerídicas. Na interesterificação química, largamente utilizada, o catalisador empregado com maior frequiência é o metóxido de sódio (MeONa), embora outras bases, ácidos e metais estejam disponíveis. Alquilatos de sódio são reconhecidamente os catalisadores mais ativos, inclusive a temperaturas relativamente baixas, entre 50 e $90{ }^{\circ} \mathrm{C}^{51}$.

No processo químico, óleos e gorduras, isentos de umidade, são aquecidos e o catalisador é adicionado em proporções apropriadas ( 0,1 a $0,5 \%)$, de forma a ocorrer sua rápida e completa dispersão na matéria-prima. A reação é conduzida por intervalo de tempo prédeterminado e finalizada mediante a adição de água, que promove a inativação do catalisador. Fatores que podem influenciar a reação incluem intensidade de agitação, temperatura e tamanho de partícula do catalisador ${ }^{52}$. Um esquema da reação de interesterificação química é ilustrado na Figura 2.

As mudanças nas propriedades de fusão e solidificação de óleos e gorduras interesterificados devem-se às proporções relativas dos componentes acilglicerídicos após o rearranjo dos ácidos graxos. Consequientemente, a estabilidade e as características inerentes de produtos interesterificados podem ser preditas. Na maioria dos casos, a interesterificação acarreta o aumento do ponto de fusão do produto, mediante a introdução de ácidos graxos saturados na posição $s n-2$ do glicerol e resultante aumento nos níveis de triacilgliceróis dissaturados e trissaturados. Logo, é possível a obtenção de produtos plásticos com consistência característica de "shortenings" "9,53. 


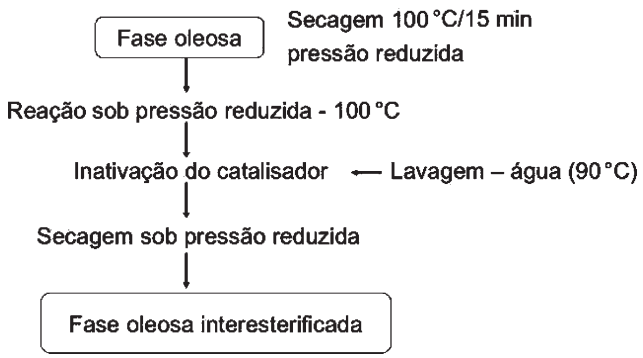

Figura 2. Esquema da reação de interesterificação química

\section{NOVAS FRAÇÕES OLEOSAS PRODUZIDAS POR INTERESTERIFICAÇÃO QUÍMICA E SUAS APLICAÇÕES EM ALIMENTOS}

A interesterificação de misturas de óleos vegetais totalmente hidrogenados ou de frações mais saturadas com óleos líquidos tem sido utilizada para produção de gorduras com ausência de AGT e com propriedades funcionais específicas ${ }^{17}$.

Zeitoun e colaboradores ${ }^{54}$ relataram a interesterificação química de óleo de soja totalmente hidrogenado, com 9 diferentes óleos vegetais: canola, soja, girassol, algodão, milho, palma, amendoim, açafrão e coco, na proporção de $1: 1$. As condições de reação corresponderam a $60 \mathrm{~min}, 95{ }^{\circ} \mathrm{C}$ e $0,3 \%$ de metóxido de sódio. Os resultados indicaram que os óleos com alto conteúdo de ácido palmítico (C16:0), notadamente óleos de palma e algodão, estiveram relacionados ao perfil de sólidos e comportamento de cristalização próprios de margarinas tradicionais.

A interesterificação de óleo de soja geneticamente modificado, com teores de ácido esteárico (C18:0) entre 17,2 e 33\%, foi realizada por List e colaboradores ${ }^{55}$. Após a reação, o perfil de sólidos indicou que amostras contendo $17 \%$ de ácido esteárico seriam compatíveis para uso em margarinas para culinária. Amostras interesterificadas com teores de ácido esteárico entre 20-33\% revelaram-se próprias para aplicação em margarinas tradicionais.

Gioielli e Baruffaldi ${ }^{56}$ em reações de interesterificação, catalisadas por metóxido de sódio, em gorduras de babaçu, óleo de palma e mistura de ambos na proporção respectiva de 60:40, alcançaram o equilíbrio da reação em $25 \mathrm{~min}$, sendo que o rearranjo provocou mudança significativa no perfil dos triacilgliceróis.

Petrauskaite e colaboradores ${ }^{17}$ relataram a interesterificação buscando obter gorduras zero-trans com características funcionais similares às gorduras comerciais disponíveis. Os experimentos foram realizados em escala laboratorial, mediante utilização de gorduras altamente saturadas (estearina de palma ou óleo de soja totalmente hidrogenado) com óleo de soja, em proporções variáveis entre 10:90 a 75:25 $(\% \mathrm{~m} / \mathrm{m})$. As condições empregadas foram 90 ${ }^{\circ} \mathrm{C}$ durante 90 min e 0,2\% de metóxido de sódio. As misturas de partida e interesterificadas foram comparadas a amostras comerciais, em termos de composição triacilglicerólica, teor de gordura sólida e nível de AGT. Misturas interesterificadas com 30-50\% de matéria-prima saturada revelaram-se semelhantes aos "shortenings" comerciais, enquanto misturas com $40 \%$ de estearina de palma ou $25 \%$ de óleo de soja totalmente hidrogenado foram indicadas para uso em produtos de confeitaria (zero trans).

O efeito da interesterificação nas características físico-químicas de sistemas ternários contendo óleo de palma ou oleína de palma, com oleína de palmiste e óleo de girassol, foi avaliado por Lida e $\mathrm{Ali}^{57}$, visando a produção de coberturas sem a presença de isômeros trans. As matérias-primas foram misturadas em 16 diferentes proporções e sujeitas à reação sob as seguintes condições: $110{ }^{\circ} \mathrm{C}, 30 \mathrm{~min}$, agitação de $500 \mathrm{rpm}$ e $0,2 \%$ de catalisador metóxido de sódio. A presença de óleo de palma e óleo de girassol colaborou para o aumento e a diminuição do ponto de fusão do produto interesterificado, respectivamente.

Kok e colaboradores ${ }^{9}$ utilizaram interesterificação de óleo de soja altamente saturado (HSSBO), contendo 23,3\% de ácido palmítico e $20,0 \%$ de ácido esteárico, na preparação de margarina sem AGT $\left(70{ }^{\circ} \mathrm{C}, 10 \mathrm{~min}, 0,5 \% \mathrm{MeONa}\right)$. Obteve-se gordura com ponto de fusão $34,5^{\circ} \mathrm{C}$, em contraste com o baixo ponto de fusão inicial $\left(9,5^{\circ} \mathrm{C}\right)$. A mistura de $50 / 50 \%$ do produto interesterificado com um óleo de soja líquido foi utilizada para produção de margarina, que apresentou pequena diferença significativa $(p \leq 0,05)$ em termos sensoriais, em relação a margarinas comerciais.

Rodriguez e colaboradores ${ }^{58}$ estudaram a interesterificação de misturas sebo/óleo de girassol com o intuito de substituir óleos marinhos hidrogenados na formulação de "shortenings". Para isso, foi utilizado um planejamento fatorial fracionário $2^{4-1}$, em que as variáveis independentes consideradas foram: proporção de sebo (50$90 \%)$, concentração de metóxido de sódio $(0,4-1,0 \% \mathrm{~m} / \mathrm{m})$, temperatura $\left(60-120^{\circ} \mathrm{C}\right)$ e tempo de reação (15-60 min). O teor de sebo, a concentração de catalisador e temperatura apresentaram efeito significativo $(\mathrm{p} \leq 0,05)$ no ponto de fusão. A interesterificação resultou em alterações nas curvas de sólidos dos referidos produtos. Para concentrações de sebo iguais a 70 e $90 \%$ obteve-se "shortenings" adequados para utilização em sorvetes e panificação, respectivamente.

Rodrigues e Gioielli59 ${ }^{59}$ relataram a interesterificação química de diferentes misturas compostas por gordura de manteiga ("butterfat") e óleo de milho, buscando bases gordurosas com as características organolépticas da manteiga, mas com alto teor de ácidos graxos $\omega-6$. Os resultados revelaram que o processo reduziu significativamente o conteúdo de triacilgliceróis trissaturados e triinsaturados das amostras interesterificadas.

Pontes e colaboradores ${ }^{60}$ avaliaram as características da gordura resultante da interesterificação química de óleo de palma (OP $75 \%$ ) e estearina de palma (EP - $25 \%$ ) realizada em planta-piloto. Os resultados obtidos foram comparados com os da mistura (OP + EP) antes da interesterificação. A amostra interesterificada apresentou teores de sólidos maiores que os da mistura na faixa analisada e o ponto de fusão passou de 39,1 para $42,2{ }^{\circ} \mathrm{C}$, conforme a Figura 3. Enquanto os triacilgliceróis mono e dissaturados diminuíram, os triinsaturados e os trissaturados aumentaram. Concluiu-se que a gordura obtida apresentou características adequadas para ser utilizada tanto para recheio de biscoito quanto para uso geral e também para bolos e pães de forma. Porém, pelo fato de ter apresentado teor de triacilgliceróis do tipo trissaturados (SSS) da ordem de $13 \%$, seu uso para recheios não foi recomendado, em função de poder apresentar certo grau de cerosidade.

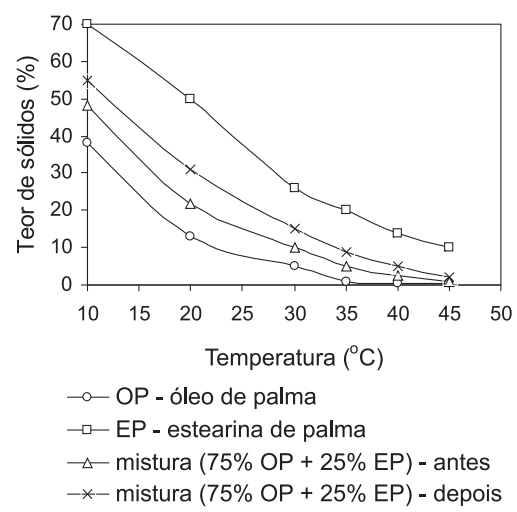

Figura 3. Curvas de sólidos das matérias-primas (OP: óleo de palma; EP: estearina de palma) e da mistura $(75 \% O P+25 \%$ EP $)$, antes e depois da interesterificação 
Norizzah e colaboradores ${ }^{48}$ estudaram a interesterificação de misturas de estearina de palma (PS) e oleína de palmiste (PKOo), nas proporções de PS:PKOo relativas a 20:80, 40:60, 60:40 e 80:20 $(\mathrm{m} / \mathrm{m})$. A reação foi conduzida a $110{ }^{\circ} \mathrm{C}$ durante $60 \mathrm{~min}$, com agitação intensa e $0,2 \%$ de $\mathrm{MeONa}$. O ponto de fusão, conteúdo de gordura sólida (SFC), composição triacilglicerídica, termograma de fusão, forma polimórfica e morfologia dos cristais foram avaliados para as misturas antes e após a interesterificação. Os resultados indicaram que todas as misturas interesterificadas apresentaram menor ponto de fusão e menores teores de triacilgliceróis altamente saturados em relação às misturas de partida. As frações obtidas foram indicadas para margarinas e "shortenings" para cremes e produtos similares.

Visando a obtenção de alternativas à hidrogenação parcial na produção de gorduras plásticas, Karabulut e colaboradores ${ }^{61}$ estudaram o processo de interesterificação em escala laboratorial. Foram utilizadas misturas de estearina de palma totalmente hidrogenada ou estearina de palma com óleos de canola e de algodão, em proporções variando de 30:70 a 70:30 (\%m/m). O processo resultou na diminuição do ponto de fusão e do teor de gordura sólida para todas as amostras, relacionada ao decréscimo no teor de triacilgliceróis trissaturados e monoinsaturados. As curvas de sólidos dos produtos interesterificados diferiram significativamente $(\mathrm{p} \leq 0,05)$ das amostras não interesterificadas e também entre si. As misturas interesterificadas com 30:70 canola/estearina de palma ou 30:70, 40:60 e 50:50 algodão/estearina de palma revelaramse adequadas à produção de "shortenings" para uso geral. Em contrapartida, misturas contendo 70:30 canola/estearina de palma totalmente hidrogenada ou 70:30 algodão/estearina de palma foram recomendadas para manufatura de margarinas. Para o emprego em confeitaria, mostraram-se factíveis as misturas de 50:50 canola/estearina de palma ou 50:50 e 60:40 algodão/estearina de palma. Os autores concluíram que o emprego destas frações pode substituir seguramente as gorduras disponíveis em questão, com ausência total de AGT.

Godoy e colaboradores ${ }^{62}$ produziram em escala piloto formulações oleosas interesterificadas a partir de misturas de óleos de palma (PO) e palmiste (PKO), visando avaliar a performance das mesmas em produtos alimentícios específicos. Além da etapa de interesterificação, o perfil de sólidos da gordura inicial foi alterado por meio de adição posterior de óleo de soja totalmente hidrogenado (HSBO), que permitiu a modificação de consistência sem a necessidade de hidrogenação parcial e, conseqüentemente, sem a possibilidade de formação de isômeros trans. Duas formulações gordurosas interesterificadas, designadas por $\mathrm{GE} 1=\mathrm{PO} / \mathrm{PKO}$ 60:40inter e $\mathrm{GE} 2=\mathrm{PO} /$ PKO 60:40inter + 3\%HSBO, foram utilizadas no teste de aplicação, por apresentarem perfil de sólidos e pontos de fusão característicos para sorvetes e bolos, respectivamente. O estudo demonstrou a aplicação com sucesso das frações interesterificadas como ingredientes para estes produtos, sem a presença de AGT em sua composição. A Figura 4 exibe o conteúdo de gordura sólida das misturas PO/PKO 60:40 antes e após interesterificação e com adição de 3\% de HSBO.

Grimaldi e colaboradores ${ }^{63}$ realizaram otimização, em escala laboratorial, da reação de interesterificação química do óleo de palma. As amostras foram submetidas a ensaio fatorial completo com 3 níveis de concentração de catalisador (metóxido de sódio comercial) e 3 níveis de tempo de reação. O processo foi desenvolvido com $100 \mathrm{~g}$ de fase oleosa, em temperatura constante de $100{ }^{\circ} \mathrm{C}$, sob agitação magnética. Os resultados da análise estatística basearam-se na maior variação dos grupos de triacilgliceróis em relação ao controle, com preferência para a condição referente a $0,4 \%$ de $\mathrm{MeONa}$ e 20 min de reação. Verificou-se aumento do teor de sólidos após o processo, evidenciando a melhoria da consistência para uso em margarinas ou produtos alimentícios.

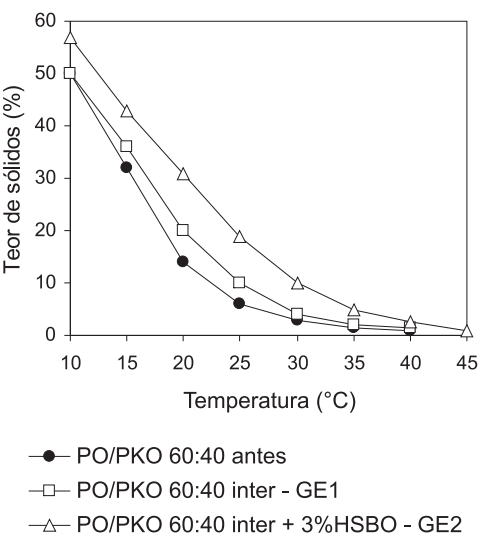

Figura 4. Curvas de sólidos das misturas PO/PKO 60:40 - antes da interesterificação, após interesterificação (GE1) e com adição de $3 \%$ de $\mathrm{HSBO}$ - óleo de soja totalmente hidrogenado (GE2)

Khatoon e Reddy ${ }^{64}$ avaliaram a obtenção de gorduras plásticas zero trans através de interesterificação de misturas de estearina de palma com óleos da manga ou mahua (Madhuca longifolia), em diferentes proporções. Os resultados mostraram que misturas de estearina de palma/mahua (1:1 e $1: 2)$ e estearina de palma/manga (1:1), após a reação $\left(1 \mathrm{~h}, 80{ }^{\circ} \mathrm{C}, 0,2 \%\right.$ metóxido de sódio $)$ exibiram perfis de sólidos similares aos "shortenings" comerciais para panificação e ao vanaspati, um tipo de gordura hidrogenada tradicional na Índia e demais países dos sudeste asiático.

Ramli e colaboradores ${ }^{65}$ relataram as alterações físico-químicas em misturas de óleo de palmiste hidrogenado e gordura proveniente do leite de cabra, após interesterificação. Os autores concluíram que o processo resultou em aumento da plasticidade das gorduras, mas não indicaram, entretanto, uma possível aplicação das mesmas em produtos alimentícios.

\section{CONCLUSÃO}

As evidências científicas relacionadas ao impacto negativo dos AGT na saúde têm fornecido subsídios para que o consumo de gordura parcialmente hidrogenada seja minimizado, fato corroborado por mudanças progressivas na legislação em diversos países.

O desafio da indústria de alimentos na substituição da gordura trans em diversos produtos reside no desenvolvimento de formulações que apresentem funcionalidade equivalente e viabilidade econômica, não acarretando, entretanto, aumento substancial do teor de ácidos graxos saturados nos alimentos.

A interesterificação química consiste em opção tecnológica importante para produção de gorduras técnicas visando diversas aplicações alimentícias, mediante a facilidade do processo e o baixo custo associado.

Embora inúmeros estudos tenham sido desenvolvidos na área, a exploração de novas matérias-primas e/ou suas combinações é fator preponderante para obtenção de novas frações gordurosas que possam ser empregadas na maior variedade possível de produtos alimentícios, sem restrições de ordem tecnológica ou funcional.

\section{REFERÊNCIAS}

1. Young, F. V. K.; J. Am. Oil Chem. Soc. 1985, 62, 372.

2. O'Brien, R. D.; Fats and Oils - Formulating and Processing for Applications, Technomic Publishing Company: Lancaster, 1998.

3. Valenzuela, A.; King, J.; Nieto, S.; Grasas y Aceites 1995, 46, 369.

4. Fritsche, J.; Steinhart, H.; Fett/Lipid 1998, 6, 190.

5. Larqué, E.; Zamora, S.; Gil, A.; Early Human Development 2001, 65, 31. 
6. Martin, C. A.; Carapelli, R. ; Visantainer, J. V.; Matsushita, M.; Souza, N. E.; Food Chem. 2005, 93, 445.

7. Hunter, E.; Nutr. Res. 2005, 25, 499.

8. Applewhite, T. H.; J. Am. Oil Chem. Soc. 1981, 58, 261.

9. Kok, L. L.; Fehr, W. R.; Hammond, E. G.; White, P. J.; J. Am. Oil Chem. Soc. 1999, 76, 1175

10. Mayamol, P. N.; Samuel, T. ; Balachandran, A.; Sundaresan, A.; Arumugham, C.; J. Am. Oil Chem. Soc. 2004, 81, 407.

11. List, G. R.; Food Technol. 2004, 35, 1015.

12. Hui, Y. H.; Bailey's industrial oil and fat products, $5^{\text {th }}$ ed., Wiley: New York, 1996.

13. Haumann, B. F.; INFORM 1994, 5, 668.

14. Ghotra, B. S.; Dyal, S. D.; Narine, S. S.; Food Res. Int. 2002, 35, 1015.

15. Woerfel, J. B.; Grasas y Aceites 1995, 46, 357.

16. Karabulut, I.; Kayahan, M.; Yaprak, S.; Food Chem. 2003, 81, 453.

17. Petrauskaite, V.; De Greyt, W.; Kellens, M.; Huyghebaert, A.; J. Am. Oil Chem. Soc. 1998, 75, 489

18. Jeyarani, T.; Reddy, S. Y.; J. Am. Oil Chem. Soc. 2003, 80, 1107.

19. Feldman, E. B.; Krisetherton, P.; Kritchevsky, D.; Lichtenstein, A. H.; Am. J. Clin. Nutr. 1996, 63, 663.

20. Chiara, V. L.; Sichieri, R.; Carvalho, T. S. F.; Rev. Nutr. 2003, 16, 227.

21. Padovese, R.; Mancini Filho, J.; Entendendo a gordura: os ácidos graxos, Ed. Manole: Barueri, 2002.

22. Block, J. M.; Barrera-Arellano, D.; Arch. Latinoam. Nutr. 1994, 44, 281

23. Basso, R.; Almeida Gonçalves, I.; Mancini Filho, J.; Bol. Soc. Bras. Ciênc. Tecnol. Aliment. 1999, 33, 57.

24. Grimaldi, R.; Gonçalves, L. A. G.; Esteves, W.; Braz. J. Food Technol. 2000, 3, 159 .

25. Badolato, E. S. G.; Dissertação de Mestrado, Universidade de São Paulo, Brasil, 2000.

26. Kawashima, L. M.; Soares, L. M. V.; Ciênc. Tecnol. Aliment. 1993, 13, 194.

27. Aued-Pimentel, S.; Caruso, M. S. F.; Cruz, J. M. M.; Kumagai, E. E.; Corrêa, D. U. O.; Rev. Inst. Adolfo Lutz 2003, 62, 131

28. Capriles, V. D.; Areas, J. A. G.; Ciênc. Tecnol. Aliment. 2005, 25, 363.

29. Garland, M.; Sacks, F. M.; Colditiz, G. A.; Rimm, E. B.; Sampson, L. A.; Willett, W. C.; Am. J. Clin. Nutr. 1998, 67, 25.

30. Chiara, V. L.; Silva, R.; Jorge, R.; Brasil, A. P.; Rev. Nutr. 2002, 15, 11.

31. Mensink, R. P.; Katan, M. B.; N. Engl. J. Med. 1990, 323, 439.

32. Enig, M. G.; Cereal Foods World 1996, 41, 58.

33. Gurr, M.; Lipid Technol. 1990, 2, 105.

34. Lichtenstein, A.; Nutr. Rev. 1993, 51, 340.

35. Mensink, R. P.; Katan, M. B.; Hornstra, G.; J. Lipid Res. 1992, 33, 1493.

36. Aro, A.; Jauhiainen, M.; Partanen, R.; Salminen, I.; Mutanen, M.; Am. J. Clin. Nutr. 1997, 65, 1419
37. Ascherio, A.; Katan, M.; Zock, P. L.; Stampfer, M. J.; Willett, W. C.; N. Engl. J. Med. 1999, 340, 1994.

38. Decker, W. J.; Mertz, W.; J. Nutr. 1967, 91, 324.

39. Zevenbergen, J. L.; Houtsmuller, V. M.; Gottenbos, J. J.; Lipids 1988, 23, 178.

40. Peacock, L. L.; Wahle, K. W.; Biochem. Soc. Trans. 1998, 17, 679.

41. Koletzko, B.; Acta Paediatr. 1992, 81, 302.

42. Carlson S.; Thomas, M. C.; Cook, H. W.; Emken, E. A.; Filer, L.; Am. J. Clin. Nutr. 1997, 119, 717.

43. Koletzko, B.; Muller, J.; Biol. Neonate. 1990, 57, 172.

44. www.cfsan.fda.gov/label.html, acessada em Dezembro 2004.

45. Brasil. Lei $\mathrm{n}^{\circ} 8078,11$ de setembro de 1990. Diário Oficial. Brasília, 12 set, 1990. Seção I (supl.). p.1-12. Dispõe sobre a proteção do consumidor.

46. www.portal.saude.gov.br/portal/saude/area, acessada em Abril 2005.

47. www.e-legis.bvs.br/leisref, acessada em Novembro 2004.

48. Norizzah, A. R.; Chong, C. L.; Cheow, C. S.; Zaliha, O.; Food Chem. 2004, $86,229$.

49. Erickson, D. R.; Practical Handbook of Soybean Processing and Utilization, AOCS Press: Champaign, Illinois, 1995.

50. Rozendaal, A.; INFORM 1992, 3, 1232.

51. Marangoni, A. G.; Rousseau, D.; Trends Food Sci. Technol. 1995, 6, 329

52. Sreenivasan, B.; J. Am. Oil Chem. Soc. 1978, 55, 796.

53. Hustedt, H. H.; J. Am. Oil Chem. Soc. 1976, 53, 390

54. Zeitoun, M. A. M.; Neff, W. E.; List, G. R.; Mounts, T. L.; J. Am. Oil Chem. Soc. 1993, 70, 467.

55. List, G. R.; Mounts, T. L.; Neff, W. E.; J. Am. Oil Chem. Soc. 1997, 74, 327.

56. Gioielli, L. A.; Baruffaldi, R.; Rev. Farm. e Bioquím. Univ. S. Paulo, 1988, 24, 29.

57. Lida, A. M. D. N.; Ali, A. R.; J. Am. Oil Chem. Soc. 1997, 75, 1625.

58. Rodriguez, A.; Castro, E.; Salinas, M. C.; López, R.; Miranda, M.; J. Am. Oil Chem. Soc. 2001, 78, 431 .

59. Rodrigues, J. N.; Gioielli, L. A.; Food Res. Int. 2003, 36, 149.

60. Pontes, A. E. R.; Aires, G. S. B.; Ormenese, R. C. S. C.; Grimaldi, R.; Gonçalves, L. A. G.; Anais do Simpósio Internacional Tendências e Inovações em Tecnologia de Óleos e Gorduras, Campinas, Brasil, 2003.

61. Karabulut, I.; Turan, S.; Ergin, G.; Eur. Food Res. Technol. 2004, $218,224$.

62. Godoy, A. M. T.; Gonçalves, L. A. G.; Silva, M. A. A. P.; Gilabert-Escrivá, M. V.; Anais do III Congreso Iberoamericano de Ingeniería de Alimentos, I Gongreso Español de Ingeniería de Alimentos, Valencia, Espanha, 2001.

63. Grimaldi, R.; Gonçalves, L. A. G.; Ando, M. Y.; Quim. Nova 2005, 28 , 633.

64. Khatoon, S.; Reddy, S. R. Y.; Eur. J. Lipid Sci. Technol. 2005, 107, 786.

65. Ramli, N.; Said, M.; Loon, N. T.; J. Food Lipids 2005, 12, 243. 